\title{
Chemostatanlage zur kontinuierlichen Kultur von Algen
}

\author{
Von Max Hirsbrunner \\ Institut für Gewässerschutz und Wassertechnologie (IGW) der Eidg. Technischen Hochschule, 'Zürich') \\ Manuskript eingegangen am 1. September 1981
}

\section{ABSTRACT}

A chemostat-apparatus for continuous culture of algae

The apparatus described was assembled using relatively inexpensive parts and makes the cultivation of various forms of algae under steady-state conditions and different flowrates (variation under $0.5 \%$ ) possible. There was no difference in the biodensity in the reactor compared to that in the outflow.

\section{Einleitung}

Die kontinuierliche Kultivation von Algen ist eine seit längerer Zeit erprobte Methode $[2,4,5,7,15,16]$. Die Nährstoffansprüche von Algen sind in kontinuierlicher Kultur weit besser überprüfbar, als dies in statischen oder semikontinuierlichen Kulturen möglich wäre. Zur Durchführung von Bio-Assays sind Chemostatkulturen die geeignetste Kulturtechnik [17]. Die im folgenden beschriebene Anlage wurde zur Ausführung von Algentests unter Standardbedingungen entwickelt.

Käuflich zu erwerbende Chemostatapparaturen sind sehr teuer. Um genügend Einrichtungen parallel betreiben zu können, ist aus relativ billigen, frei erhältlichen Einzelteilen die nachfolgend beschriebene Anlage zusammengestellt worden. Verschiedene Gesichtspunkte wurden bei der Konstruktion der Kultureinheit berücksichtigt:

\section{- Variables Kulturvolumen.}

- Als Auslauf dient ein zentral angeordnetes Rohr. Die Algensuspension gelangt auf kürzestem Weg ins Auffanggefäss.

- Alle $\mathrm{Zu}$ - und Ableitungen des Reaktorgefässes müssen so ausgelegt sein, dass auch bei wochenlangem Betrieb keine Sekundärinfektionen auftreten.

- Die Reaktorgefässe sollen allen Algen möglichst gleichmässige Licht- und Nährstoffverhältnisse bieten. Eine zylindrische Gestalt bietet die besten Voraussetzungen dazu. Toträume sollen soweit als möglich vermieden werden.

1) Die Arbeit wurde an der Eidg. Anstalt für Wasserversorgung, Abwasserreinigung und Gewässerschutz (EAWAG) ausgeführt. 
- Die Dosiereinrichtung muss auch bei Dauerbetrieb genau und reproduzierbar arbeiten. Eine präzis arbeitende Schlauchquetschpumpe, die auch kleine Mengen zu dosieren vermag, ist Voraussetzung dazu.

- Die Vorratsgefässe müssen über eine Sterilfiltrationseinrichtung auffüllbar sein, da bei Hitzesterilisation des Nährmediums Gefahr besteht, dass hitzeempfindliche Stoffe ausgefällt werden.

\section{Konzept der Anlage}

\subsection{Die Kultureinheit (Abbildung)}

Die Anlage gliedert sich in verschiedene Einheiten:

- Kultivationsgefäss,

- Vorratsgefässe mit Zuleitung und Dosierpumpe,

- Begasungseinrichtung,

- regelbare Lichtquelle.

Im folgenden werden die einzelnen Baugruppen näher beschrieben.

\subsection{Kultivationsgefäss}

Das verwendete Kultivationsgefäss (1) hat ein maximales Kulturvolumen von 2,5 Liter. Es handelt sich um ein zylindrisches Reaktionsgefäss mit Planschliffdeckel (Firma Schmizo, Zofingen, Schweiz, Nr.626, Schliffdurchmesser $137 \mathrm{~mm}$ ). Es sind verschiedene Planschliffdeckel erhältlich (Nr.631 a). Mit einer Spannvorrichtung, die gleichzeitig als Halterung dient, wird das Gefäss abgedichtet. Als Dichtung dient ein in die eingeschliffene Nut eingelegter O-Ring aus Viton. Anstelle der üblichen Normschliffanschlüsse wurde das Gewindeverbindungssystem SVL (Sovirel, Levallois, France) gewählt. Am Planschliffdeckel wurden vier Gewinde SVL 15 und zentral ein Gewinde SVL 22 aufgesetzt. Das SVL-System arbeitet mit Teflondichtungen; fettfreie Verbindungen gewährleisten eine grosse Flexibilität in der Wahl der Zuleitungsrohre.

Das Ablaufsystem funktioniert wie der Auslauf eines Brunnens. In einem seitlich eingepassten Stutzen mit SVL-15-Gewinde (2) kann das Ablaufrohr (3) eingesetzt werden. Durch die jeweils gewählte Länge des Ablaufrohres wird das Kulturvolumen nach Belieben eingestellt. Das genaue Kulturvolumen wird bei Versuchsabbruch volumetrisch bestimmt. Die Algensuspension gelangt über eine Bakterienfalle (4) direkt ins Auffanggefäss (5). Der leichte Überdruck im Reaktorgefäss bewirkt ein sauberes Abfliessen der Algenlösung.

Die Zuleitungen bestehen aus Silikonkautschukschlauch und passenden Glasrohren. Die Schlauchleitungen sind durch Glasmuffen trennbar gehalten, welche, mit Alufolie abgedeckt, nach der Dampfsterilisation wieder zusammengesteckt werden. Die Anlage kann so in kleinen Autoklaven sterilisiert werden.

Zur ständigen Durchmischung der Kultur dient ein Teflonmagnetrührer (6) mit Wulst, um einen «Kugelmühleneffekt» auszuschalten. Die Zufuhr der Luft endet im Stutzen des Auslaufrohres (7). Dadurch können sich in diesem Bereich die Algen nicht absetzen. Über einen zentral im Deckel angeordneten Einfüllstutzen (8) kann 
das Nährmedium ins Gefäss eingefüllt werden. Die Impfung mit Algen geschieht durch eine mit Schraubendeckel versehene Öffnung (9). Die Probenahme erfolgt über ein Kapillarrohr (10) in eine Saugflasche (11). Die Dosierleitung endet mit einer Kapillarröhre (12) im unteren Teil des Kulturgefässes.

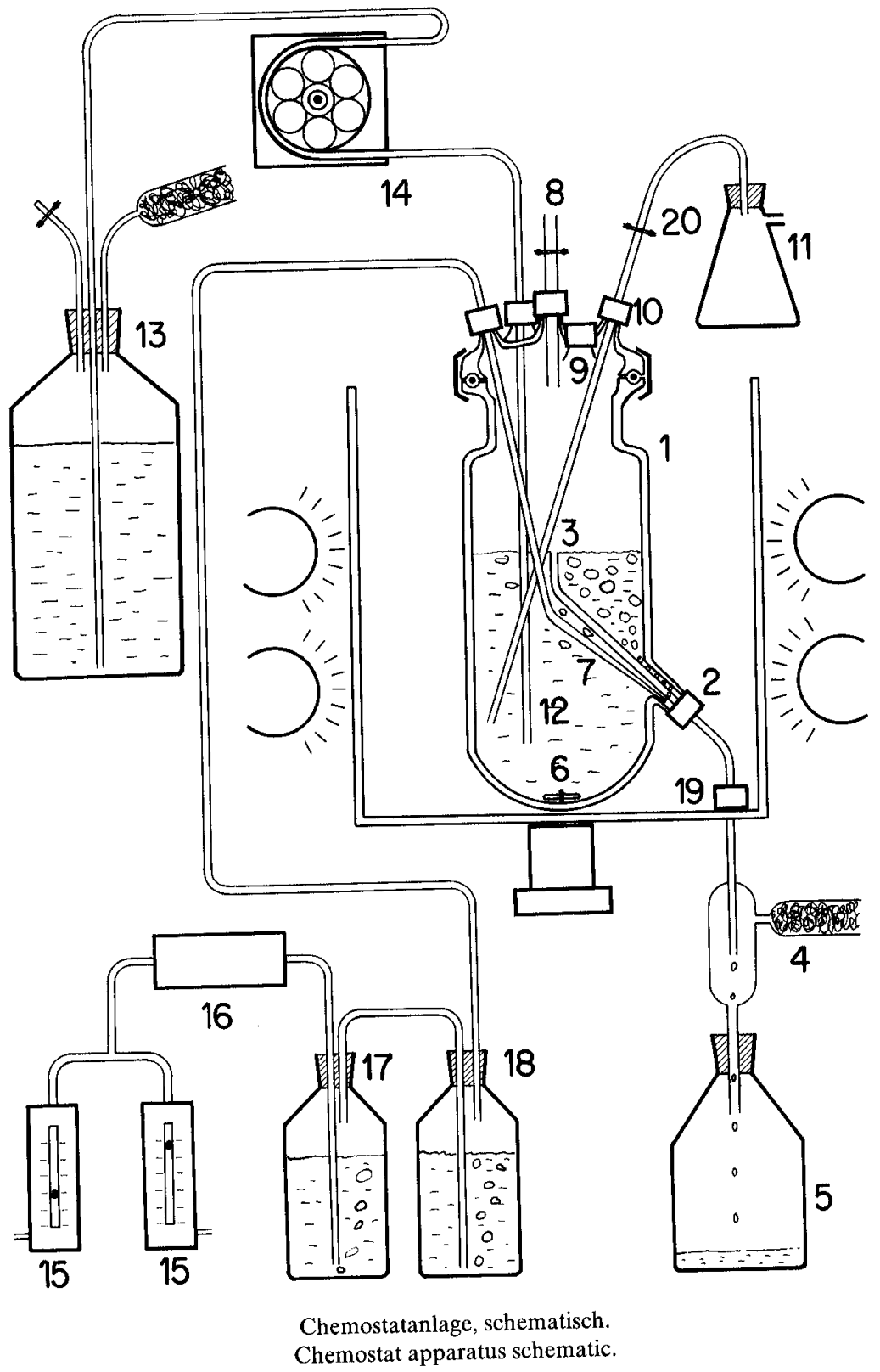




\subsection{Vorratsgefässe und Dosierung}

Als Vorratsgefässe eignen sich genügend grosse Enghalsflaschen (13) (z. B. 20 Liter), die mit Silikonkautschukstopfen verschlossen sind. Darin eingesetzt sind das Belüftungsrohr mit Wattestopfen als Bakterienfalle, die Zuleitung, nach dem Auffüllen mit einer Schlauchklemme verschliessbar, sowie das Ansaugrohr (Kapillarrohr) der Pumpe.

Die Dosierung der Nährlösung geschieht mit einer Persistaltikpumpe (14) (Perpex, Firma Meyer, Luzern). Bei diesem Pumpensystem ist der Getriebeteil austauschbar. Durch die Wahl verschiedener Untersetzungen kann die Flussrate im Bereich von 2 bis $300 \mathrm{ml} / \mathrm{h}$ variiert werden (Schwankungen unter 0,5\%). Die Flussrate ändert sich bei einer bestimmten Untersetzung von Versuch zu Versuch bis zu $20 \%$, je nachdem der Pumpenschlauch locker oder straff in den Kopf eingelegt wird. Die gewünschte Flussrate lässt sich durch entsprechendes Strecken des Schlauches auf den notwendigen Wert einstellen. Die Betriebssicherheit der verwendeten Peristaltikpumpe ist sehr hoch. Die mechanische Beanspruchung des Schlauches ist optimal, ein Zerreissen und die damit verbundene Infektionsgefahr für die Algensuspension im Reaktor ist bislang nicht aufgetreten.

\subsection{Begasungseinrichtung}

Zur Dosierung der Luft- und Kohlendioxidmenge stehen zwei Rotameter (15) mit verschiedenen Messrohren im Einsatz (Brooks, Typ 1355-V, Messrohre R-2-15-B und R-6-15-B; Firma A. Bohny, Basel). Die Luft und das Kohlendioxid werden über ein Bakterienfilter (16) entkeimt und in einer grossen Gaswaschflasche (17) von mindestens 10 Liter Inhalt befeuchtet. Gegebenenfalls kann vorhandener Ammoniak durch eine mit Zinkchlorid oder Schwefelsäure (2\%) gefüllte Waschflasche (18) aufgefangen werden.

Die Kontrolle des $\mathrm{pH}-$ Wertes der Algensuspension geschieht mit der Zudosierung von entsprechenden Mengen $\mathrm{CO}_{2}$ (je nach Milieu bis $5 \mathrm{Vol} . \%$ der zugegebenen Luftmenge). Der pH-Wert lässt sich auf 0,2 Einheiten genau kontrollieren. Gewisse Schwankungen müssen bei dieser einfachen $\mathrm{pH}-$ Kontrolle in Kauf genommen werden: durch regelmässige Überprüfung können sie jedoch in engen Grenzen gehalten werden.

\subsection{Lichtquelle}

4 Leuchtstoffröhren (Philips ThF/33 $40 \mathrm{~W}$ ) sind so angeordnet, dass das Kulturgefäss in seiner ganzen Höhe ausgeleuchtet ist. Mit einem Lichtmessgerät kann im Zentrum eines leeren Kulturgefässes die Lichtmenge bestimmt werden. Als Lichtregler sind auf dem Markt verschiedene Fabrikate erhältlich, deren Schaltung auf dem Phasenanschnittprinzip beruht (z. B. Vario 6, Firma Leuenberger, Oberglatt $\mathrm{ZH})$. Die Lichtverteilung innerhalb des Reaktors ist nicht gleichmässig. Verschiedene Untersuchungen haben sich mit diesem Problem auseinandergesetzt; so haben Loogman und van Liere [13] in einem ähnlich gebauten Reaktorgefäss unter verschiedenen Bedingungen die Lichtverhältnisse gemessen. Die dauernde und 
intensive Durchmischung der Algensuspension reduziert den Einfluss der unterschiedlichen Lichtverteilung auf das Wachstum auf ein vernachlässigbares Minimum.

\subsection{Temperaturregelung}

Die Kulturgefässe stehen in einer Plexiglaswanne (Wandstärke $1 \mathrm{~cm}$ ), mit eingepasster Durchführung (19) für das Ablaufrohr. Das Rohr wird wiederum durch ein in der Wanne eingepasstes SVL-15-Gewinde fixiert. Das Wasser in der Plexiglaswanne kann über einen Kryostaten auf die gewünschte Kultivationstemperatur eingestellt und gegen allfällige Infektion mit einer schwachen Zugabe eines Desinfektionsmittels entkeimt werden.

Die Wanne mit den Kulturgefässen ist in einem eigens dazu gefertigten Gestell untergebracht.

\subsection{Filtration und Inbetriebnahme der Anlage}

Zur Filtration der Nährlösung wird ein Druckfilter (Sartorius SM 16269, Filterdurchmesser $142 \mathrm{~mm}$ ) mit einem Glasfaserfilter (Sartorius SM 13400) als Vorfilter und einem Membranfilter von 0,2 $\mu \mathrm{m}$ Porenweite (Sartorius SM 11307) verwendet. Die Filtriereinheit, der Reaktor und die Vorratsgefässe werden bei Standardbedingungen sterilisiert.

Nach dem Zusammenbau wird die Nährlösung über den Druckfilter in das Reaktorgefäss und in die Vorratsflaschen eingefüllt. Die Algensuspension wird durch den Impfstutzen (9) zugesetzt. Die Anzucht der Kultur erfolgt bei ausgeschalteter Dosierpumpe direkt im Reaktor.

\section{Betrieb der Anlage}

\subsection{Probenahme}

Kleinere Mengen der Algensuspension werden mit Hilfe von sterilen Pipetten durch den Impfstutzen (9) entnommen und dieser nachher mit einem sterilen Schraubdekkel wieder verschlossen.

Grössere Mengen von Algensuspension werden über ein Absaugrohr (10) unter leichtem Vakuum in eine kleine Saugflasche (11) $(250 \mathrm{ml})$ abgesaugt. Dabei wird die Schlauchklemme (20) geöffnet und nach dem Absaugen des Vorlaufes (ca.10 ml) wieder geschlossen. Der Vorlauf wird verworfen. Jetzt kann die gewünschte Probemenge dem Reaktor entnommen werden.

\subsection{Betriebserfahrungen}

Die beschriebene Anlage wird seit dem Jahr 1973 für die Beantwortung verschiedenster Fragestellungen algenphysiologischer und ökologischer Art benutzt. So hat Hirsbrunner [11] Algentestversuche, Ühlinger [19] autökologische Untersuchungen an Aphanizomenon flos-aquae durchgeführt und Gavrieli [10] die Nährstoffaufnah- 
me von Pediastrum boryanum bei Steady-state-Bedingungen abgeklärt. Bundi [3] benutzte die Einrichtung zur Zucht von standardisierten Algen. Stöckli [18] hat mit einer geringen Änderung die Luft- und Substratzufuhr zu einer Einheit verbunden, um begeisselte Algenformen am Hochkriechen in der Nährstoffzuleitung zu hindern.

Die Dichte der Kultur im Reaktor entspricht im Verhältnis derjenigen im Ausfluss. Verschiedene Autoren $[1,8,12]$ haben in Kulturen mit fädigen Formen im Ausfluss geringere Dichten als im Reaktor erhalten. Feuillade und Feuillade [9] schlagen ein Überlaufsystem vor, das diesem Problem entgegenwirkt. Mit unserem zentral angeordneten Auslauf konnten selbst bei der Kultur fädiger Formen keine ins Gewicht fallenden Dichteunterschiede gemessen werden.

\section{Zusammenfassung}

Die beschriebene Anlage dient zur Kultivation von Algen bei Steady-state-Bedingungen. Das Kulturvolumen im Reaktor ist beliebig einstellbar, es beträgt maximal 2,5 Liter. Der zentral angeordnete Auslauf mündet in einem nachträglich in die Reaktorwand eingepassten Auslaufstutzen. Anstelle von Normschliffen wird mit einem Gewindesystem (SVL, Sovirel, France) gearbeitet, das für die Auslegung der $\mathrm{Zu}$ - und Ableitungen einen grossen Spielraum bietet.

Die Beleuchtung wird über ein Lichtregelgerät, die gewünschte Kulturtemperatur über einen Kryostaten eingestellt. Zur Dosierung steht eine Peristaltikpumpe im Einsatz, die selbst bei längeren Versuchsperioden eine konstante Flussrate (Schwankungen unter $0,5 \%$ ) liefert.

Mit der beschriebenen Anlage sind verschiedene kokkale, fadenförmige und auch begeisselte Algenformen bei Steady-state-Konditionen mit unterschiedlichen Flussraten gezüchtet worden. Unterschiede in bezug auf die Biomassedichten im Reaktor und im Auslauf konnten keine registriert werden.

\section{SUMMARY}

The installation described serves the culturing of algae at steady-state conditions. The culture volume in the reactor can be choosen freely up to a maximum of 2.5 liters. The centrally arranged outflow leads into a drain fitted in the reactor wall. Instead of ground-fittings a screw-fitting system (SVL, Sovirel, France) is used, which offers large freedom of movement for the layout of the supply- and drainagesystems.

The lighting is adjusted by a light regulator and the desired culture temperature maintained by a cryostat. A constant dosage is attained with a peristaltic pump which, even over longer experimental periods variates less than $0.5 \%$.

With the described installation various algae have been cultured, especially coccales, filiformes and flagellates at steady-state conditions with different flow rates. There was no difference in the biodensity in the reactor compared to that in the outflow.

\section{RÉSUMÉ}

L'installation décrite sert à la cultivation d'algues aux conditions d'un steady state. Le volume de cultures dans le réacteur peut être réglé à volonté, il contient 2,5 litres au maximum. Le tuyau d'écoulement placé au centre aboutit dans un évacuateur installé postérieurement dans la paroi du réacteur. Au lieu de 
travailler avec des rodages normalisés on adopte un système de vis (SVL, Sovirel, France) qui offre de grandes possibilités pour la disposition des conduites d'arrivage et d'évacuation.

L'éclairage est conditionné par un régleur de lumière et la température choisie des cultures se maintient par un cryostat. Une pompe à péristaltique fournit très régulièrement une quantité de milieu nutritif même pendant des périodes expérimentales de lonque durée (perturbation sous $0,5 \%$ ).

Des diverses formes d'algues, notamment des coccales, filiformes et des flagellées ont été cultivées dans cette installation sous des conditions de steady avec des quantités variables de milieu nutritif. Il n'y a pas de différences de densité d'algues entre le réacteur et l'écoulement.

\section{LITERATURVERZEICHNIS}

1 Algren, G.: Growth of Oscillatoria agardhii in chemostat culture. 1. Nitrogen and phosphorus requirements. Oikos 29, 209-224 (1977).

2 Bringmann, G., und Kühn, R.: Bestimmung der biologisch wirksamen Beschaffenheit von Schlammproben aus Gewässern nach dem BMT-Verfahren. Gesundheitsingenieur 89/2, 48-60 (1968).

3 Bundi, Th.: Untersuchungen zur Aufnahme von Kupfer durch Chlorella pyrenoidosa in Abhängigkeit der Kupferspeziierung. Diss. ETH, Nr.6553.

4 Caperon, J., und Meyer, J.: Nitrogen growth of marine phytoplankton. I. Changes in population characteristics with steady state growth rate. Deep-Sea Res. 19, 601 (1972).

5 Carpenter, E. J.: A simple, inextensive algal chemostat. Limnol. Oceanogr. 13/4, 720 (1968).

6 Droop, M.R.: Vitamin $B_{12}$ and marine ecology III: an experiment with a chemostat. J. mar. biol. Ass. U.K. 46 (1966).

7 Eichhorn, M.: Zur Stoffproduktion kontinuierlicher Kulturen von Scenedesmus obliquus (Turp.) Kützing im Dauerlicht bei Phosphat- und Nitratlimitation. Flora, Abt. A, 159, 494-606 (1969).

8 Feuillade, J.B., und Feuillade, M.G.: Etude des besoins en azote et en phosphore d'Oscillatoria rubescens D.C. à l'aide de culture en chemostat. Verh. int. Verein Limnol. 19/4, 2698-2708 (1975).

9 Feuillade, J.B., und Feuillade, M.G.: A chemostat device adapted to planctonic Oscillatoria cultivation. Limnol. Oceanogr. 24/3, 562-564 (1979).

10 Gavrieli, J.: The determination of $\mathrm{K}_{\mathrm{S}}$ for phosphate and nitrate for Pediastrum boryanum using the DROOP and CAPERON models for steady state growth of algae. EAWAG, Limnol. Abteilung, unveröffentlicht.

11 Hirsbrunner, M.: Die Entwicklung von Standard-Bioassay-Verfahren im Vergleich zu in situVerfahren. Diss. ETH, in Vorbereitung.

12 Liere, L. van, et al.: Growth of Oscillatoria agardhii Gom. Hydrobiol. Bull. 9/2, 62-70 (1975).

13 Loogman, J.P., und Liere, L. van: An improved method for measuring irradiance in algal cultures. Verh. int. Verein Limnol. 20/4, 2322-2328 (1978).

14 Maddux, W.S., und Jones, R. F.: Some interactions of temperature, light and nutrient concentration during the continuous culture of Nitzschia closterium and Tetraselmis sp. Limnol. Oceanogr. 9, 79-86 (1964).

15 Müller, H.: Wachstum und Phosphatbedarf von Nitzschia actinastroides (Lemm.) v. Goor in statischer und homokontinuierlicher Kultur unter Phosphatlimitierung. Arch. Hydrobiol Suppl. 38/ 4, 399-484 (1972).

16 PAAP (Provisional Algal Assay Procedure). Joint Industry/Goverment Task Force on Eutrophication, New York, N.Y., 1969.

17 Soeder, C.J., et al.: Mineral nutrition of planctonic algae: some considerations, some experiments. Mitt. int. Verein Limnol. 19, 39-58 (1971).

18 Stöckli, A.: Diss. ETH, in Vorbereitung.

19 Ühlinger, U.F.: Untersuchungen zur Autökologie der planktischen Blaualge Aphanizomenon flosaquae. Diss. ETH, Nr.6723, ADAG Administration \& Druck AG, 1980.

Adresse des Autors: Max Hirsbrunner, dipl. sc. nat., Bollackerweg 29, CH-5024 Küttigen. 